\title{
Arsenic polluted groundwater: epidemiological study and efficient removal method
}

\author{
G. Badalians Gholikandi ${ }^{1}$, M. Sadrzadeh Ardebili ${ }^{2}$, R. Riahi ${ }^{1}$ \\ \& H. R. Orumieh ${ }^{3}$ \\ ${ }^{1}$ Power and Water University of Technology (PWUT), \\ Water Research Institute (WRI), Iran \\ ${ }^{2}$ Tehran University, Iran \\ ${ }^{3}$ Pars Arianab Consulting Engineers, Isfahan, Iran
}

\begin{abstract}
Arsenic is mainly found throughout the crust in arsenic sulfide, metal arsenate and arsenide forms. The pollution of the ground water in some regions in the west of Iran, especially in Kurdistan province, which is above the allowable range $(0.01 \mathrm{mg} / \mathrm{lit})$, requires an optimum technical and economic solution for its removal. This research investigated the epidemiological situation and the feasibility of removal of arsenic from groundwater using the best efficient method considering local, economical and technical parameters. Field monitoring of water resources showed that in seven villages the arsenic concentration was higher than the WHO guideline $(10 \mu \mathrm{g} / \mathrm{L}$ to $<500 \mu \mathrm{g} / \mathrm{L})$. Using a logistic regression model, there is found to be a significant relation between lifetime relative intake of arsenic from drinking water and hyperkeratosis and also hyper pigmentation. Correlation between hyperkeratosis and hyper pigmentation is considerable. According to results of hair analysis, arsenic concentration in hair is from 0.021 to 3.41 with average of $0.56 \mathrm{mg} / \mathrm{kg}$. There is a close relation between hair arsenic and total arsenic intake via drinking water. After investigation of the epidemiological and environmental parameters, two pilot studies, modified activated alumina and the softening method, were considered. According to the results of the modified activated alumina pilot study, it has high efficiency for arsenic removal. The adsorption isotherm for both species of arsenic (III and V) is compatible with both Freundlich and Langmuier models. The results of the softening pilot studies show that in $\mathrm{pH}>10.5$ removal is done up to about $90 \%$ and for the initial arsenic
\end{abstract}


concentrations up to $0.2 \mathrm{mg} / \mathrm{lit}$, the percentage of arsenic removal is independent of its concentration in raw water.

Keywords: arsenic, ground water, epidemiology, removal efficiency.

\section{Introduction}

Arsenic is a grey element in crystalline form. Its atomic number is 33 , its atomic weight is 74.92 , and its density is 5.727 ; the element's melting point is $817^{\circ} \mathrm{C}$ and its sublimation is $613^{\circ} \mathrm{C}$. The main resources of arsenic are minerals, settlements, soils and atmosphere. The arsenic content of the soil is usually increased in regions with gold, silver minerals and zinc and lead sulfides. In raw water, arsenic is found in two organic and inorganic forms; but the quantity of the inorganic arsenic is higher. The chemical valence of the arsenic and its type depends on the oxidation and reduction conditions and water $\mathrm{pH}$. Depending on water $\mathrm{pH}$, arsenic is found in four dissolved forms in the soil: $\mathrm{H}_{3} \mathrm{ASO}_{4}, \mathrm{H}_{2} \mathrm{ASO}_{4}{ }^{-}$, $\mathrm{HASO}_{4}{ }^{2-}, \mathrm{ASO}_{4}{ }^{3-}$, and is also found in five other forms: $\mathrm{H}_{2} \mathrm{ASO}_{3}{ }^{-}, \mathrm{HASO}_{3}{ }^{3-}$, $\mathrm{ASO}_{3}{ }^{3-}, \mathrm{H}_{4} \mathrm{ASO}_{3}{ }^{+}$, and $\mathrm{H}_{3} \mathrm{ASO}_{3}$. In $\mathrm{pH}<9$ arsenic is neutral and in $\mathrm{pH}>9$ is ionic. Generally, the organic compounds of the element are toxic and three-valence arsenic is more harmful than five-valence. The sever arsenic intoxication occurs when the element affects the neural system which may cause coma and, in intoxications with 70-80 mg / lit, may be ever mortal. Digestive system, neural system, respiratory system and skin all are highly sensitive to the element and arsenic may cause skin cancer, keratosis and hyper pigmentation [3, 11]. The World Health Organization (WHO) and US Environmental Protection Agency (EPA), in majority of their issues, have determined the maximum allowable arsenic content of the drinking water $0.01 \mathrm{mg} / \mathrm{lit}[4,5]$. The common technologies used for arsenic removal from drinking water include coagulation together with filtration and softening by lime on the basis of adsorption and sedimentation of arsenic with metal hydroxides. Other probable technologies of arsenic removal may include greensand, manganese, reverse osmosis, reverse electro dialysis (RED), and adsorption by use of active carbon. In small scales, ion exchange resins or active aluminum oxide are also used [2, 6, 7]. Long-term consumption of drinking water contaminated with arsenic can cause adverse health effects such as skin lesions and lesions and cancer in humans. Present research aimed to study this subject in two phases. Adverse health effects of arsenic in drinking water of Kurdistan province are studied during first phase [10]. In the second phase, the efficiency of two arsenic removal methods is considered.

\section{Epidemiological studies}

The main Objectives were determination of skin lesions (Hyperkeratosis and hyper pigmentation) and hypertension between residence of eight contaminated and uncontaminated villages in Kurdistan province. 752 persons were studied at 7 villages. After assessment of accuracy and precision of two field and laboratory methods for measurement of arsenic in drinking water, presence of 
arsenic and other heavy metals in water resources was determined and total relative intake dose of arsenic from drinking water during lifetime was calculated for each person.39 hair samples as biomarker for arsenic was gathered from females of 3 villages at 3 exposure levels, without exposure, low exposure and high exposure respectively and analyzed with neutron activation method.

Field monitoring of water resources showed that in 36 villages out of the 44 villages arsenic levels were less than World Health Organization (WHO) guideline $(10 \mu \mathrm{g} / \mathrm{L})$. But in 7 villages the arsenic levels were higher than WHO guideline. The range of arsenic concentration was between $10 \mu \mathrm{g} / \mathrm{L}<$ to 500 $\mu \mathrm{g} / \mathrm{L}$. The highest level was measured in a spring $(1500 \mu \mathrm{g} / \mathrm{L})$. Arsenic (V) is predominant specie $(>90 \%$ of arsenic). The results show that 49 persons $(6.5 \%)$ suffer from hyperkeratosis and 20 persons $(2.7 \%)$ have hyper pigmentation. Correlation between hyperkeratosis and hyper pigmentation is considerable. Using Logistic regression model (Forward Method) there is significant relation between lifetime relative intake of arsenic from drinking water and hyperkeratosis $(\mathrm{OR}=1.14, \mathrm{CI}=95 \%)$ and also hyper pigmentation $(\mathrm{OR}=1.245$, $\mathrm{CI}=95 \%$ ). Systolic blood pressure in the groups with high and very high exposure to arsenic was higher than those of the groups without or with little exposure. However, a similar pattern is not observed for high diastolic blood pressure. No significant relation was observed between either age $(p=0.16)$ or sex $(p=0.88)$ and hyperkeratosis (in the presence of arsenic intake). Similarly, the relation between either age $(\mathrm{p}=0.09)$ or $\operatorname{sex}(\mathrm{p}=0.95)$ and hyper pigmentation was not significant, considering arsenic pollution as a variable in the model. According to result of hair analysis, arsenic concentration in hair is from 0.021 to 3.41 with average of $0.56 \mathrm{mg} / \mathrm{kg}$. In the unexposed people, people with low exposure and for people with disrupted high exposure in the past time the average concentration is $0.06,0.30$ and $1.21 \mathrm{mg} / \mathrm{kg}$ respectively. There is a close relation between hair arsenic and total arsenic intake via drinking water (Pearson correlation coefficient $=0.711, \mathrm{p}<0.001$ ) Also the relation between current arsenic content of drinking water and arsenic concentration in hair $(\mathrm{R}=0.662 \mathrm{p}<0.001)$ was statistically significant. Total arsenic intake via drinking water increased by 2.69 gr. $(95 \%$ confidence interval $=1.80-3.59)$ for each $\mathrm{mg}$ increase in hair arsenic, and this is not affected by age of participants.

\section{Pilot studies}

Two pilot studies are considered.

\subsection{Modified activated alumina}

According to results of pilot study, modified activated alumina has high efficiency for removal of arsenic and can reduce arsenic concentration under WHO guideline. Adsorption isotherm for both species of arsenic (III and V) is compatible with both Freundlich and Langmuier models (correlation coefficient $>0.93$ ). Removal efficiency increases as a result of increasing dose and reaches to $98 \%$ for As (V) during 2 hrs. Adsorption is first order reaction and removal 
rate for concentration of 0.421 and $1.15 \mathrm{mg} / \mathrm{L}$ was $91 \%$ and $66 \%$ respectively. Removal efficiency increases 1.54 times from $61 \%$ to $94 \%$ with increasing of adsorption time from $15 \mathrm{~min}$ to $60 \mathrm{~min}$ for primary concentration of $0.25 \mathrm{mg} / \mathrm{L}$. For As (III) the highest removal was $30 \%$ with adsorbent dose $=2 \mathrm{~g} / \mathrm{L}$. Our study showed that absorption of arsenic has direct relation with increasing of $\mathrm{pH}$ up to 8 , then decrease with increasing of $\mathrm{pH}$ up to 14 . For arsenate the highest removal was observed at $\mathrm{pH}$ between 6-8 and removal efficiency was higher than $90 \%$. The highest removal for primary concentration of $0.5 \mathrm{mg} / \mathrm{L}$ with adsorbent dose $=2 \mathrm{~g} / \mathrm{L}$, was $95 \%$ at $\mathrm{pH}=8$ that achieved during $2 \mathrm{hrs}$. Totally for activated alumina used at research $\mathrm{pH}$ cannot affect removal efficiency. The prevalent $\mathrm{pH}$ range was between6-8 at monitored water resources. Chloride ion could decrease adsorption of activated alumina $2.3 \%$. For sulphate this rate was $11 \%$ Oxidation with $4 \mathrm{mg} / \mathrm{L}$ chlorine could convert $99 \%$ of As (III) to As (V) (primary conc. Of As $=0.55 \mathrm{mg} / \mathrm{L}$ Chlorine this amount was $61 \%$. Removal of As (III) using chlorine oxidation increased from $19.6 \%$ to $94 \%$ at $\mathrm{pH}=6$. Column study showed that treatment system is able to remove arsenic of water containing $1 \mathrm{mg} / \mathrm{L} \mathrm{As}(\mathrm{V})$ up to $19000 \mathrm{BVs}$ with $\mathrm{EBCT}=10 \mathrm{~min}$ that equal to 133 operation days With half EBCT (5min) the treated BVs decreased to 17000 (70 operation days) [10].

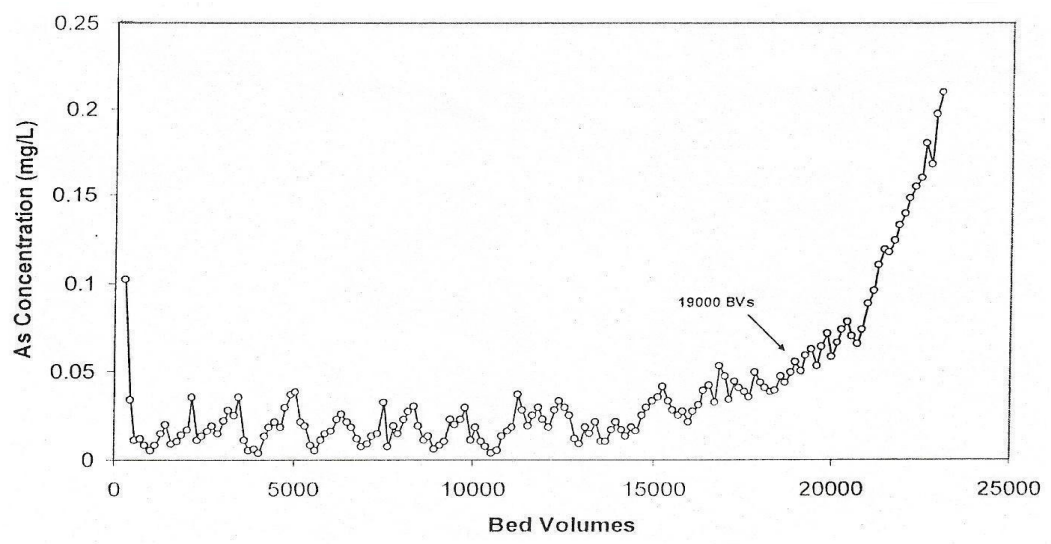

Figure 1: Pilot results in the removal of As (V) with EBCT $=5 \mathrm{~min}$, $\mathrm{Co}=1 \mathrm{mg} / 1$.

\subsection{Softening method}

The softening by lime method is normally used for decreasing the water hardness. The water hardness is the result of calcium and magnesium ions content of water, which are removed through the relevant process in the form of $\mathrm{CaCO}_{3}$ and $\mathrm{Mg}(\mathrm{OH})_{2}$ precipitates $[6,8]$.

The process is used for removal of heavy metals, dissolved minerals and viruses which are removed through adsorption and occlusion by calcium carbonate and magnesium hydroxide. The process ordinary includes rapid 
mixing with lime, coagulation of solids and sedimentation. These three stages are often done in a unique unit such as softening unit which the materials combine with the solids and/or form an occlusion with them. For softening, the lime is used separately and/or in combination with soda; the selection of each of the forms depends on the type of hardness. The lime is used for raw waters with low hardness or for waters with carbonate hardness; in cases where the hardness is caused by a non-carbonate material, the lime and/or lime with soda is used. Sometimes, the caustic soda is also used instead of lime and / or lime and soda for decrease of the produced sludge (decreases the content of the dissolved solids but the produced sludge is less).In this study, for attainment to a comprehensive result, while focusing on the removal efficiency, we also used the results of the pilot test.

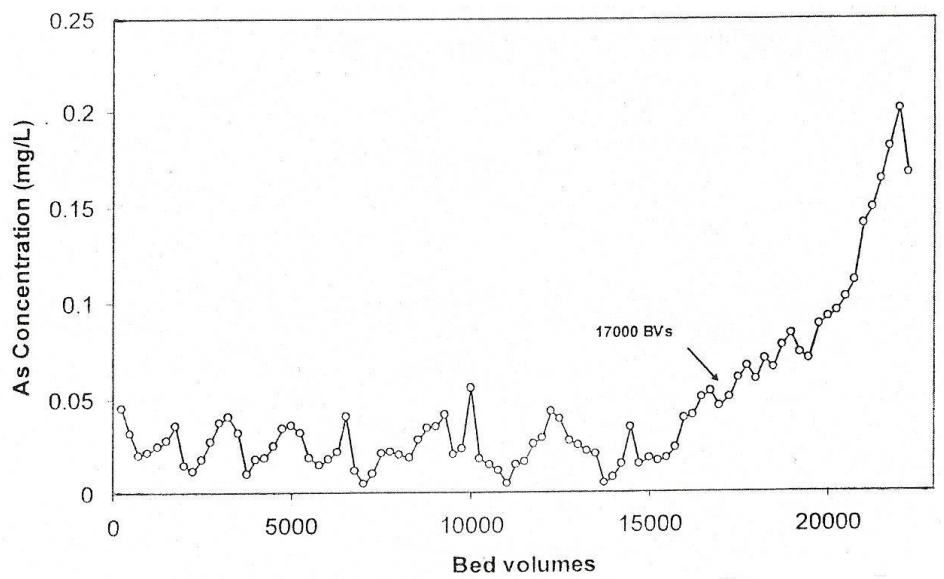

Figure 2: Pilot results in the removal of As (III) with EBCT $=5 \mathrm{~min}$, $\mathrm{Co}=1 \mathrm{mg} / 1$.

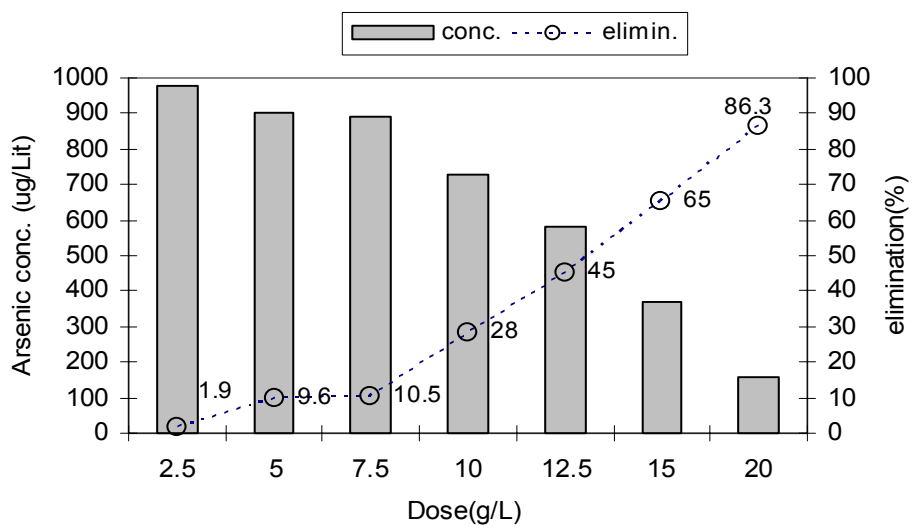

Figure 3: Arsenic removal with activated alumina, arsenic primary concentration $1 \mathrm{mg} / \mathrm{l}$ and 2 hours for adsorption time. 
138 Environmental Health Risk V

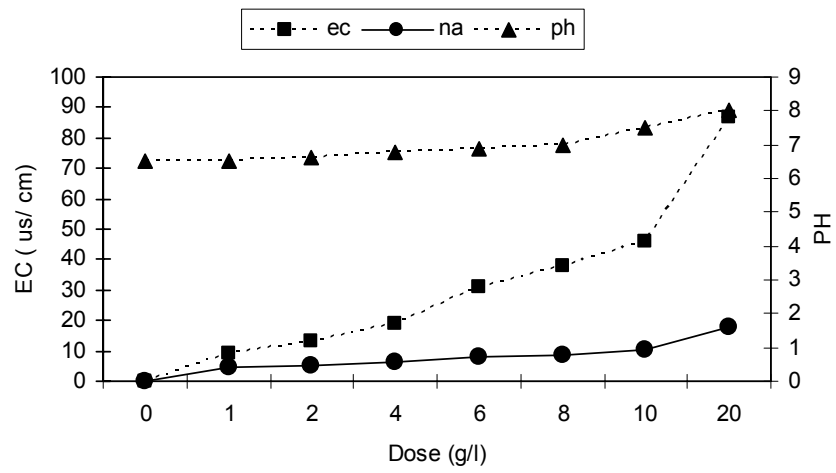

Figure 4: Influence of activated alumina on water quality.

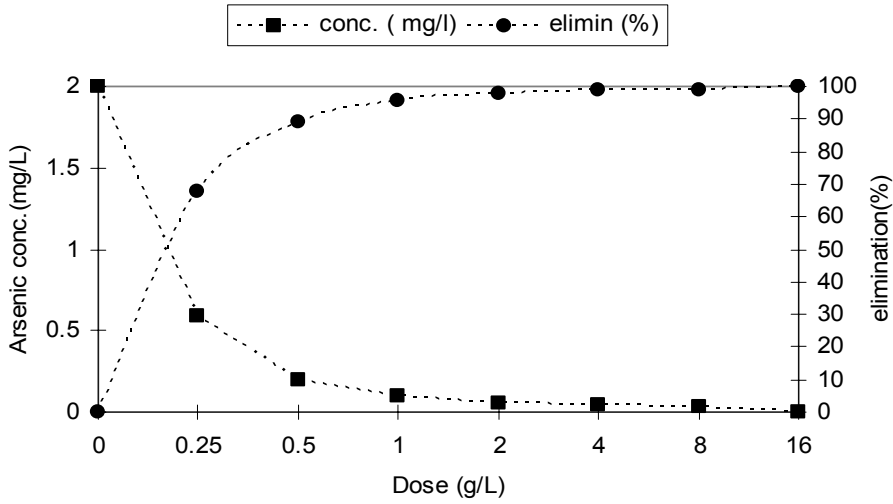

Figure 5: Adsorption of As (V) with activated alumina, arsenic primary concentration $2 \mathrm{mg} / \mathrm{l}$, experience time 24 hours.

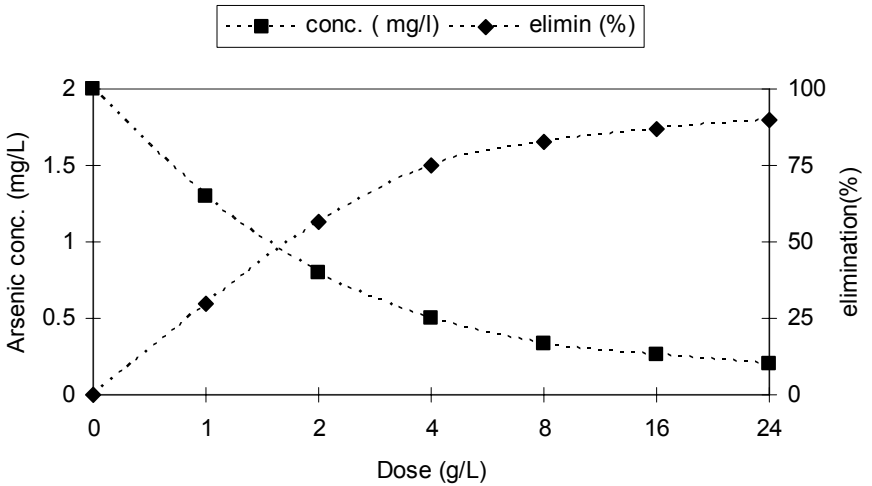

Figure 6: Adsorption of As (III) with activated alumina, arsenic primary concentration $2 \mathrm{mg} / \mathrm{l}$, experience time 24 hours. 


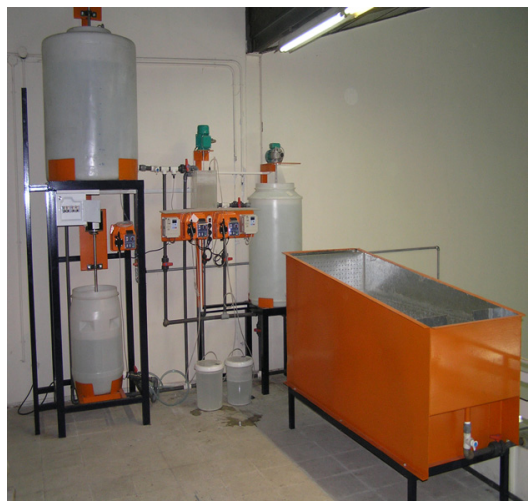

Figure 7: $\quad$ Pilot equipment.

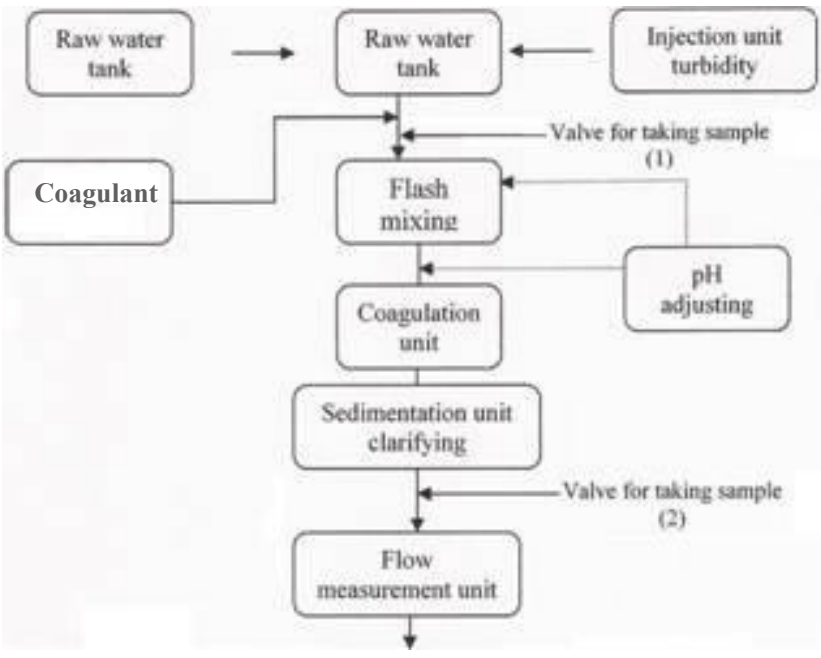

Figure 8: $\quad$ All units of the pilot plant.

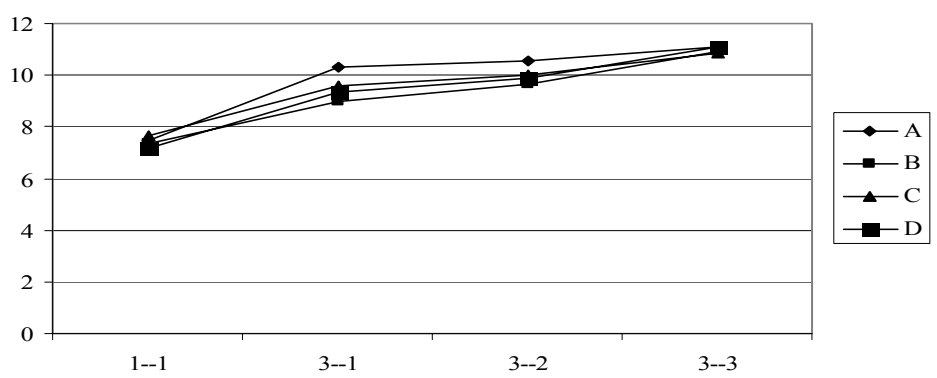

Figure 9: Variation of $\mathrm{pH}$. 
140 Environmental Health Risk V

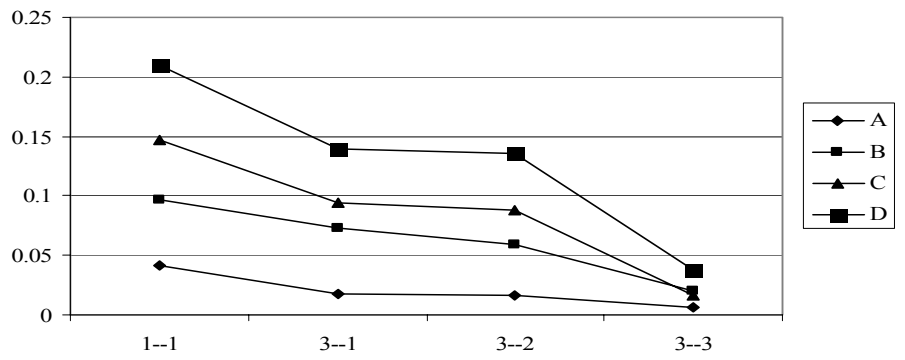

Figure 10: $\quad$ Primary arsenic concentration (mg/lit).

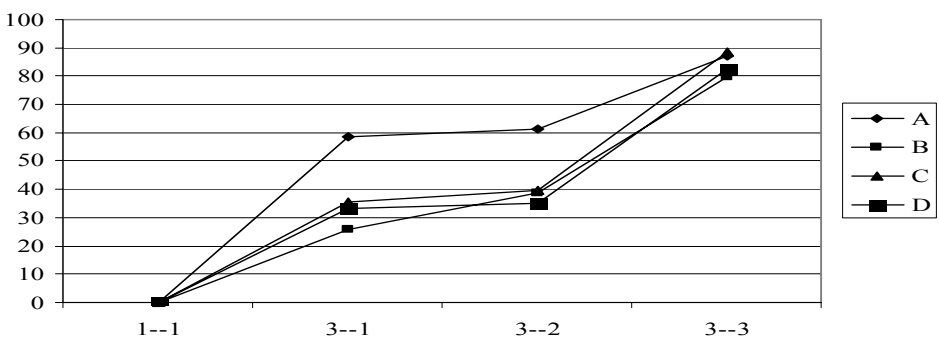

Figure 11: Percentage of removal arsenic.

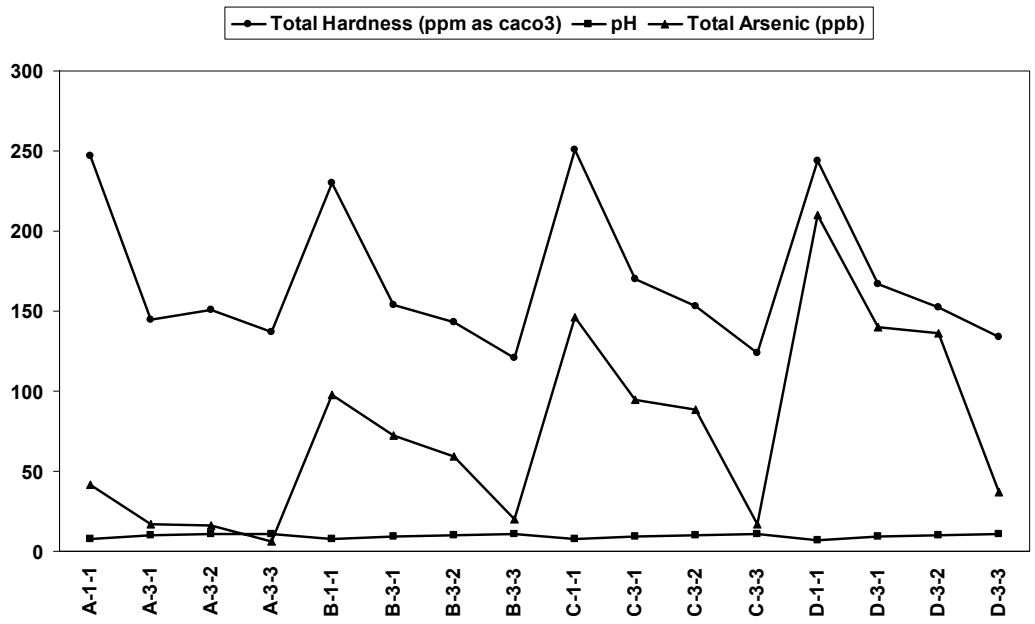

Figure 12: $\quad$ Percentage of removal arsenic. 
The relation between the change in arsenic concentration and its removal rate as results of the tests indicate, for the initial arsenic concentrations up to $0.2 \mathrm{mg} / 1$ the arsenic removal operates independent with its concentration in the raw water.

The relation between the change in arsenic concentration removal with $\mathrm{pH}$ the test results show that the arsenic removal percent in $\mathrm{pH}<10$ is about 30 to 40 percent and in $\mathrm{pH}>10.5$ is 60 to 90 percent. Therefore, the arsenic removal percent in softening treatment method by lime has a direct relation with $\mathrm{pH}$.

In other words, the arsenic removal mechanism is adsorption with magnesium hydroxide ions. On the basis of the results of the performed analysis and the above-mentioned facts, we can conclude that: The arsenic removal percent in softening method with lime for the initial concentration up to $0.2 \mathrm{mg} / \mathrm{l}$ is independent to its concentration in raw water. The arsenic removal efficiency in softening process has a direct relation with $\mathrm{pH}$; the removal rate in $\mathrm{pH}<10$ is 30 to 40 percent while in $\mathrm{pH}>10.5$ this rate increases to 60 to 90 percent. Considering the ease of execution, exploitation, operation and the adequate efficiency of the process, it is suitable process for treatment of arsenic containing waters (up to $0.2 \mathrm{mg} / \mathrm{l}$ ) in rural regions and small communities in the regions.

As the water $\mathrm{pH}$ increases as a result of softening with lime, for stabilization of water, $\mathrm{CO}_{2}$ should be added to the process.

\section{Conclusion}

Long-term consumption of arsenic contaminated groundwater for drinking in west Iran, in some villages of province Kurdistan caused adverse health effects such as skin lesions. The results of epidemiological studies show that it is significant relation between lifetime relative intake of arsenic from drinking water and hyperkeratosis and also hyper pigmentation.

After primary feasibility studies, two pilot plants were designed and performed to investigate the best method for removal arsenic, considering the local situation. Considering the ease of performance and operation of the process, the softening method is more suitable for treatment of arsenic containing water, up to $0.2 \mathrm{mg} / 1$ in rural areas and small communities in this region. Otherwise, it must be considered to use modified activated alumina.

\section{Acknowledgements}

Financial support was provided by the National Water and Wastewater Company (NWWC) and also the National Planning and Budget Organization. Special thanks go to the Water and Wastewater Authority of the Province of Kurdistan and also the Faculty for Hygiene of the University of Tehran.

\section{References}

[1] Badalians Gholikandi, G, Abbaspour, R, Technical and financial Analysis of Groundwater remediation system, chemical contaminants treatment, national research program, PWUT, Tehran, 2006. 
[2] American Society of Civil Engineers (ASCE), Ground water Protection, Remediation and Strategies, New York.

[3] Borneff, J, Hygiene, Thieme Verlag, Stuttgart, 1991.

[4] World Health Organization, (WHO), Guidelines for Drinking Water Quality, Arsenic and Arsenic Compounds, Arsenic in Drinking Water, Geneva, 2001.

[5] US Environmental Protection Agency (EPA), Research Plan for Arsenic in Drinking Water, Arsenic in Drinking Water - Treatment, Technologies and Costs for Removal of Arsenic from Drinking Water, National Primary Drinking Water Regulation, Office of Ground Water \& Drinking Water, 2001.

[6] Grombach, P, Handbuch der Wasserversorgung, Muenchen, 2000.

[7] Groundwater Remediation and Treatment Technologies, by Nicholas P. Cheremisinoff, 1998.

[8] Chemical Water and Wastewater Treatment, by H. Hahn et.al, London, 2002.

[9] Kurdistan province Rural Water and Wastewater Report, 2005.

[10] Mosaferi, M, Arsenic in drinking water of Kurdistan province, treatment considerations, 2004.

[11] Operational and Process Units in Environmental Engineering, Tom. D. Reynolds, Paul E. Richards, 2002.

[12] Water Chemistry, Gagik Badalians Gholikandi, Published by Noorpardazan, Tehran, 2003. 